\title{
Comparing importance-performance analysis and three-factor theory in assessing rider satisfaction with transit
}

\author{
Jason Cao \\ University of Minnesota \\ cao@umn.edu
}

\author{
Xiaoshu Cao \\ Shaanxi Normal University and Sun \\ Yat-Sen University \\ caoxsh@mail.sys.edu.cn
}

\begin{abstract}
Transit ridership depends on its quality of service. Many studies have analyzed rider satisfaction surveys to explore important service attributes and/or identify improvement priorities. Importanceperformance analysis (IPA) is capable of serving both purposes. However, it assumes that service attributes have a symmetric influence on rider satisfaction. To relax the assumption, this study applies threefactor theory to classify service attributes into basic, performance, and excitement factors. Using the 2013 data of bus, bus rapid transit (BRT), and metro transit riders from Guangzhou, China, it compares the results from two alternative IPA and two applications of the threefactor theory. Explicit IPA and implicit IPA classify service attributes somewhat differently but produce similar improvement priorities. For the three-factor theory, the importance grid yields more plausible results than regression with dummy variables. This study further concludes divergent improvement priorities for different services: comfort while waiting at station/stop and service reliability for bus; safety while waiting, safety while riding, and comfort while waiting for BRT; and spatial coverage for metro transit. If resources are abundant, transit agencies could also improve customer service for bus and comfort while riding for BRT.
\end{abstract}

\section{Article history:}

Received: May 9, 2016

Received in revised form: February 17, 2017

Accepted: February 19, 2017

Available online: June 27, 2017

\section{Introduction}

Transit rider satisfaction has important implications for ridership growth and financial sustainability of transit agencies. Which service attributes are critical to rider satisfaction. Travel time reliability, easy access to transit, or safety of the areas around transit stations. Which attributes are more important than others in affecting rider satisfaction. Further, because transit agencies often do not have adequate funding, which attributes of existing service should be prioritized. All of these questions are central to the operation of transit agencies. Accordingly, many studies used rider satisfaction surveys to evaluate transit quality of service and identify potential performance improvements (Guirao, García-Pastor, \& López-Lambas, 2016; Mouwen, 2015; Ojo, 2017; Shen, Xiao, \& Wang, 2016), in order to improve

Copyright 2017 Jason Cao \& Xiaoshu Cao

http://dx.doi.org/10.5198/jtlu.2017.907

ISSN: 1938-7849 | Licensed under the Creative Commons Attribution - Noncommercial License 3.0

The Journal of Transport and Land Use is the official journal of the World Society for Transport and Land Use (WSTLUR) and is published and sponsored by the University of Minnesota Center for Transportation Studies. This paper is also published with additional sponsorship from WSTLUR. 
rider experience, enhance the loyalty of existing riders, and attract new riders (dell'Olio, Ibeas, \& Cecín, 2010).

Various approaches were used to analyze satisfaction surveys (de Oña \& de Ońa, 2015). Disaggregate studies often emphasize exploring significant service attributes (van Lierop \& El-Geneidy, 2016; Verbich \& El-Geneidy, 2016), assessing their relative importance (Cain, Flynn, McCourt, \& Reyes, 2009), and identifying improvement priorities of existing services (Figler, Sriraj, Welch, \& Yavuz, 2011). Importance-performance analysis (quadrant analysis) is capable of addressing these questions at once. However, it assumes that service attributes have a linear and symmetric influence on rider satisfaction (Matzler, Bailom, Hinterhuber, Renzl, \& Pichler, 2004). This assumption overlooks different ways in which service attributes impact rider satisfaction. The three-factor theory relaxes the assumption (Kano, Seraku, Takahashi, \& Tsuji, 1984; Matzler et al., 2004). Although it is widely studied in the marketing literature and employed in service, tourism, and so on (Azzopardi \& Nash, 2013; Busacca \& Padula, 2005; Matzler, Sauerwein, \& Heischmidt, 2003), its application in transportation is scarce (Zhang \& Nagpure, 2015).

Using the 2013 rider surveys of bus rapid transit (BRT), bus, and metro transit in Guangzhou, China, this study compares and contrasts two specifications of the importance-performance analysis and two applications of the three-factor theory. It aims to answer the following two sets of research questions: (1) Which service attributes are important to rider satisfaction? Which should be prioritized over others? How do the answers to the two questions diverge by different types of transit? (2) How the results of these alternative model specifications differ. It is worth noting that Guangzhou BRT has the highest service frequency throughout the world: 350 buses per hour in a single direction. It has the second highest average daily ridership ( 1 million passengers) after Bogota's TransMilenio ${ }^{1}$. The paper is organized as follows. The next section reviews the literature from the perspective of methodologies used to analyze customer satisfaction surveys. Section 3 presents the data, variables, and modeling approaches. Section 4 discusses research results. The final section summarizes key findings.

\section{$2 \quad$ Literature review}

\subsection{Transit rider satisfaction}

Transit quality of service measures the performance of transit services from riders' perspective. It constitutes two broad categories: availability, and comfort and convenience. The former consists of spatial availability, information availability, temporal availability, and capacity availability, and the latter includes travel time, travel costs, reliability, safety and security, facility amenities, and so on (TCRP, 2003). These factors play an important role in affecting transit ridership, which is a critical indicator for the performance of transit agencies. However, given the diverse factors, transit planners are interested in which of them have critical impacts on quality of service (dell'Olio, Ibeas, \& Cecin, 2011).

Customer satisfaction survey (CSS) is a common instrument that scholars and practitioners use to assess transit quality of service (Eboli \& Mazzulla, 2007; Grisé \& El-Geneidy, 2017). In CSS, transit riders are often asked to indicate the degree to which they are satisfied with various service attributes and overall transit service (Weinstein, 2000). Many approaches have been employed to analyze CSS. A study by de Oña and de Oña (2015) classified them into five groups. aggregate performance-expectation models, aggregate models based only on performance, disaggregate models based on performance only, disaggregate performance-expectation models, and others. They offered a detailed review of these approaches, their strengths and weaknesses, and made recommendations for future research. Our review focuses on disaggregate models and their extensions.

Previous studies applied various statistical methods to examine the relationships between transit

\footnotetext{
${ }^{1}$ https://en.wikipedia.org/wiki/Guangzhou_Bus_Rapid_Transit, accessed on February 16, 2017
} 
service attributes and overall satisfaction, in order to identify key influential attributes on rider satisfaction (Cain, Flynn, McCourt, \& Reyes, 2009; Eboli \& Mazzulla, 2007; Hensher, Mulley, \& Yahya, 2010; Mouwen, 2015; Tyrinopoulos \& Antoniou, 2008). These methods consist of bivariate correlation, regression analysis, and structure equations model (including path analysis) (de Oña \& de Ońa, 2015). In these models, overall satisfaction is often chosen as the dependent variable while independent variables include, but are not limited to, satisfactions with or perceptions of individual service attributes. For example, Cao, Cao, Zhang, and Huang (2016) developed a trivariate ordered probit model to assess the relative importance of different service attributes to riders of bus, BRT, and metro transit, using the same data of this study. They found that ease of use is the most important attribute for all three types of transit; safety while riding and comfort while waiting rank second and third for bus and BRT riders whereas comfort while riding and convenience of service are the second and third important attributes for metro transit riders. Based on a structural equations model, Eboli and Mazzulla (2015) concluded that information, cleanliness, on time performance, and service frequency are the most important for of rail passengers in Italy. Using CCS from London, Verbich \& El-Geneidy (2016) developed logistic regression to examine service attributes related to satisfaction of encumbered riders and disabled riders. They found that the former value shelter condition and seat availability whereas the latter think information, travel time, and reliability important. Although these studies have identified service attributes key to rider satisfaction, they have yet to inform transit agencies which attributes of the existing service should be prioritized for improvements. This information is important for planning practice because funding is often inadequate. To answer this question, it is necessary to consider the performance of these service attributes.

\subsection{Importance-performance analysis (IPA) and revised IPA}

Importance-performance analysis has been used to identify service improvement priorities (Figler et al., 2011; Iseki \& Taylor, 2010; Weinstein, 2000). Based on the relative importance and performance of service attributes, they can be classified into four groups (Figure 1). Since the attributes in the second quadrant are of high importance but low performance, they are service improvement priorities. In the literature, the importance of service attributes can be asked explicitly in the CSS or implicitly derived through statistical analyses (de Oña \& de Oña, 2015). Early IPA applications use explicit importance. These applications are built on two assumptions: (1) attribute importance and performance are independent; and (2) the effect of an attribute on overall satisfaction is linear and symmetric (Matzler et al., 2004). Because of the inter-dependence between explicit importance and performance, implicit importance is proposed to replace explicit importance. For example, Figler et al. (2011) computed the bivariate correlations of various service attributes to overall satisfaction and then produced an implicit importance index using the ratio between the correlation of an attribute and the median correlation of all the attributes. By comparing the implicit importance and service performance in a 2008 survey, they concluded that safety and reliability are top priorities for Chicago Transit Authority.

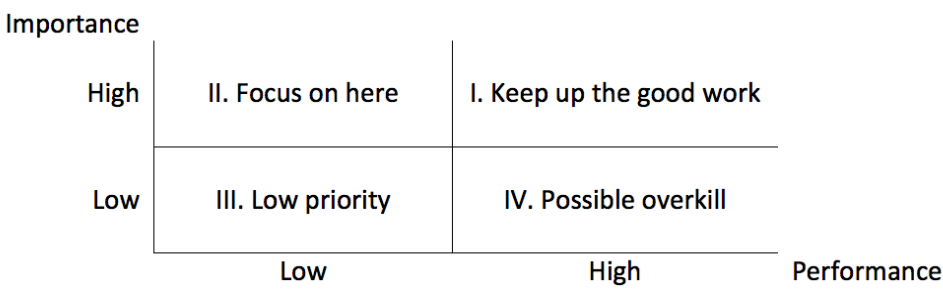

Figure 1: Important performance analysis

Note: Adapted from Martilla and James (1977) 
The three-factor theory was employed to relax the second assumption of the IPA (Matzler et al., 2003). Based on the seminal work by Kano et al. (1984) and its derivatives, service attributes can be classified into three groups. basic factors, performance factors, and excitement factors. As shown in Figure 2, basic factors adversely affect overall satisfaction if their performance is low, but do not materially affect overall satisfaction if they perform well. That is, they are dissatisfiers. By contrast, excitement factors improve overall satisfaction if their performance is high, but do not influence overall satisfaction if they perform poorly. In other words, they are unexpected and delighting. These two factors represent nonlinear and asymmetric influences of service attributes on overall satisfaction. On the other hand, performance factors tend to have a linear influence on overall satisfaction.

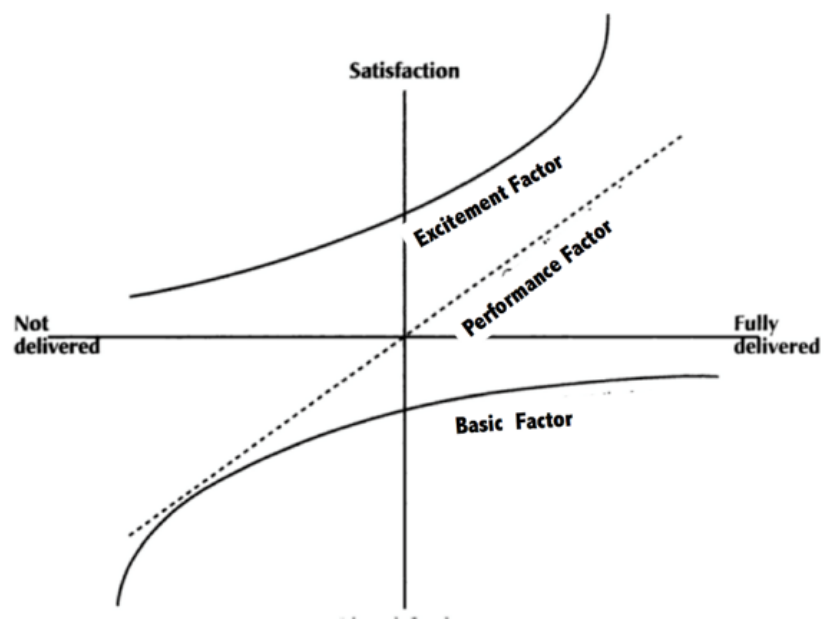

Figure 2: Kano's three factors

Note: Adapted from Vavra (1997)

Several approaches were used to identify the three factors (Busacca \& Padula, 2005). The importance grid, originated from IBM Consulting Group, was applied in the transit literature (Zhang \& Nagpure, 2015). Within this framework, respondents tend to state basic factors important (i.e., high explicit importance), but their contribution to overall satisfaction is rather low (i.e., low implicit importance) because of their "dissatisfier" characteristic. So basic factors fall into the fourth quadrant in Figure 3. On the other hand, excitement factors are unexpected (i.e., low explicit importance) but tend to have a substantial impact on overall satisfaction (i.e., high implicit importance) because of their "delighting" characteristic (Busacca \& Padula, 2005). Thus, the attributes in the second quadrant are excitement factors. Attributes in Quadrant I and III are performance factors. However, key performance factors in the first quadrant have both high explicit importance and high implicit importance, whereas unimportant performance factors in the third quadrant have both low explicit importance and low implicit importance. Using the 2013 data from Indore, India, Zhang and Nagpure (2015) found that three types of transit service tend to have different sets of three factors. Based on the three factors and their relative performance, the authors identified improvement priorities for the three types of transit. 


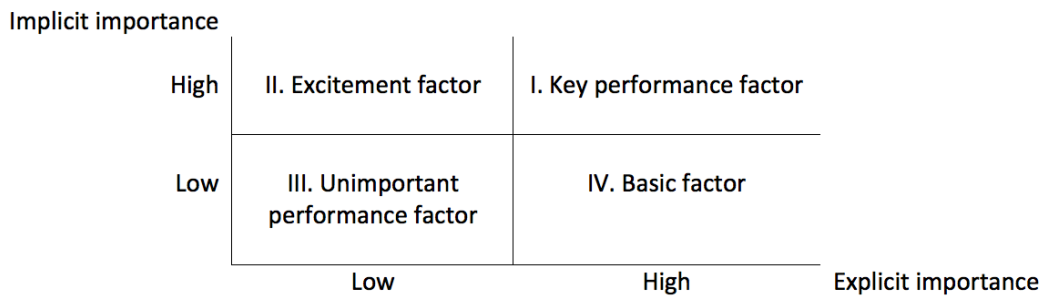

Figure 3: Important performance analysis

Note: Adapted from Vavra (1997)

Regression with dummy variables is an alternative application of the three-factor theory (Busacca \& Padula, 2005). In particular, each of all service attributes is recoded into two dummy variables that indicate low performance and high performance of the attribute, respectively, with the average performance being the reference category. Then, statistical models are developed to assess the contributions of these dummy variables to overall satisfaction. If the low performance dummy of an attribute is significant but its high performance dummy is insignificant, it will significantly affect overall satisfaction when it performs poorly but will not significantly affect overall satisfaction when it performs well. By definition, the attribute is a basic factor. By contrast, if the high performance dummy of an attribute is significant but its low performance dummy is insignificant, it will not significantly affect overall satisfaction when it performs poorly but will significantly affect overall satisfaction when it performs well. So it is an excitement factor. When both dummy variables of an attribute are significant, it has a significant and linear influence on overall satisfaction. Thus, it is a key performance factor. If neither of the dummy variables are significant, it is an unimportant performance factor by definition. Using a sample of graduate and undergraduate students on a topic in mobile communication industry in Italy, Busacca and Padula (2005) assessed the reliability of the importance grid and regression with dummy variables, found divergent results, and concluded the superiority of the latter approach. However, we have yet to see an application of regression with dummy variables in the field of transportation.

To our knowledge, Zhang and Nagpure (2015) is the only application of the three-factor theory in the transit literature. No studies have compared empirical results based on alternative applications of IPA and the three-factor theory and assessed the implications of these evolving methods to service quality management. This study aims to shed light on the gap.

\section{$3 \quad$ Methodology}

\subsection{Data and variables}

The data used in this study were collected to study the Guangzhou BRT and compare the BRT with conventional bus and metro transit. Guangzhou (or Canton) is the capital city of Guangdong province in South China. It is $120 \mathrm{~km}$ northwest of Hong Kong. It had about 13 million people in 2010 and is the third largest city in China. Guangzhou has a relatively balanced mode share. In 2005, walking and biking accounted for $47 \%$, automobiles and motorcycles shouldered $25 \%$, and transit shared $25 \%$.

Guangzhou BRT commenced in 2010. It operates on the dedicated innermost lanes along the Zhongshan Avenue, located in the central business district. It has 26 stations starting at Tianhe Sports Center and ending at Xiayuan. The line serves 31 regular BRT routes, and 5 express routes and 6 short routes during peak hours. Among them, one route runs exclusively on the dedicated lane. Other BRT routes share bus-only lanes with other buses when they run outside of the Zhongshan Avenue. 
Guangzhou BRT received a "Gold" ranking from the Institute for Transportation and Development in 2010. Its featuring attributes include dedicated right-of-way with transit signal priority; enhanced station with shelters, benches and real-time traveler information displays; advanced pre-board fare collection systems; level boarding and multi-door boarding; improved security through surveillance at stations and on board; next stop announcements; and integration with other modes such as bus, metro, and bike-sharing. These attributes play an important role in creating a positive image.

The BRT data were collected from riders at the 20 stations from Sports Center to Huangpu Coach Station in July and August 2013 (Figure 4). The corridor is served by three types of transit: BRT, conventional bus, and metro transit. Since we will compare rider satisfaction of all three types of transit, we administered the same survey to riders at metro stations and bus stops in the corridor while we were collecting data from BRT riders. Table 1 illustrates some characteristics of the three types of transit in the corridor. Flat fare is applied to conventional bus and BRT whereas Metro fare is distance-based. All three types of transit start operation almost at the same time, but bus has extended night owl hours, compared with BRT and Metro. All three types of transit are high-frequency services, even during nonpeak hours. Metro service is the most frequent, followed by BRT and then bus. Transit operating speed, passenger load, and on-time performance follow the same pattern. Metro ranks the best and bus ranks the lowest.

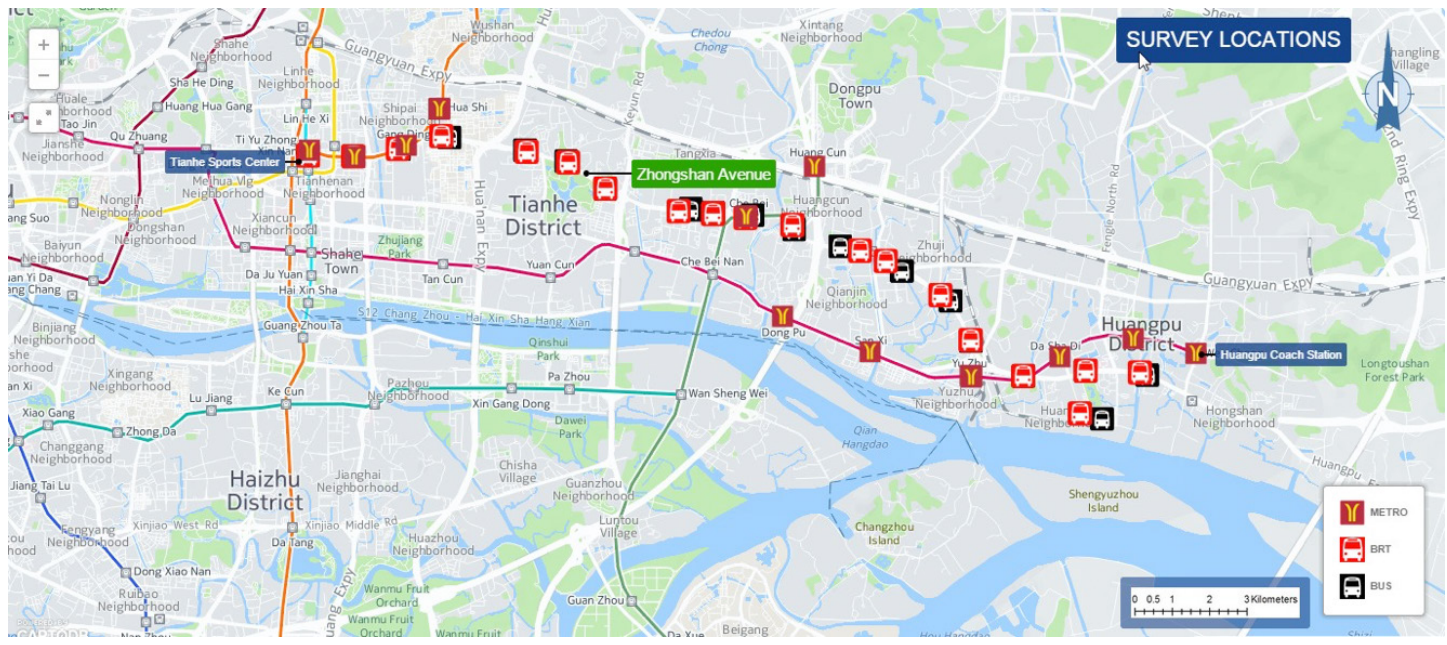

Figure 4: Survey locations

Table 1: Transit service attributes

\begin{tabular}{l|c|c|c}
\hline Characteristics & Bus & BRT & Metro \\
\hline Fare (Yuan) & 2 & 2 & 2-9 based on trip distance \\
\hline Service span & $5: 30 \mathrm{am}$ to $1: 40 \mathrm{am}$ & 6 am to 11:00 pm & 6 am to 11:30 pm \\
\hline Headway (Minute) & $6-10$ & $\begin{array}{c}\text { Peak hours: } 5 \\
\text { Nonpeak hours: on average 6.7 }\end{array}$ & $\begin{array}{c}\text { Peak hours: } 3-4.5 \\
\text { Nonpeak hours: } 4.5-7.5\end{array}$ \\
\hline Operating speed (Km/hour) & $\begin{array}{c}\text { Peak hours: } 11-13 \\
\text { Nonpeak hours: } 15-20\end{array}$ & $\begin{array}{c}\text { Peak hours: } 21 \\
\text { Nonpeak hours: } 33\end{array}$ & $50-60$ \\
\hline Peak hour passenger load & Very crowded & Crowded but better than bus & Extremely crowded (crush load) \\
\hline On-time performance & Worst & Good & Best \\
\hline
\end{tabular}


Since BRT is implemented primarily to mitigate congestion, we chose to survey riders from morning peak to evening peak during weekdays. Undergraduate and graduate students of a few universities in Guangzhou administered the survey after appropriate training. The surveyors randomly chose passengers at stations/stops and briefly explained survey purpose while handing out the cover letter. Respondents were then asked to fill out the questionnaire after their consent. The surveyors answered clarification questions when asked. We asked the surveyor to board with passengers if they were unable to complete the survey while waiting.

The four-page survey includes three sections. In Section A, we ask respondents to report their transit use and information related to their ongoing trip including origin and destination, distance, modes of access/egress, travel time and cost. Section B contains a list of socio-demographics including gender, age, education, driver's license, employment status, income, household size, and car ownership. In Section $\mathrm{C}$, we ask respondents to assess the importance and performance of 13 service attributes. The attributes are designed by Cain et al. (2009), based on literature review and a focus-group study. In particular, we ask respondents to indicate the importance of 13 attributes in affecting whether or not they use transit. For each of the three types of transit, respondents are then asked to rate the attributes and to indicate their overall opinion of transit service on a five-point ordinal scale ranging from "Very Poor" (1) to "Very Good" (5). They are asked to offer their impression even if they have not used a particular transit before. The 13 attributes cover different dimensions of quality of service. To facilitate understanding, we offer descriptions in parenthesis for most attributes in the survey. Specifically, the 13 attributes include door to door travel time, safety while at station/stop (safety from accidents and/or crime), travel cost (transit fares, related cost like parking and rickshaw/taxi), frequency of service (how often service runs), comfort while riding (seats available, temperature, smooth ride, cleanliness, etc.), hours of service (how early or late service runs, and/or weekend hours), other riders (feeling secure/at ease/compatible with other riders), convenience of service (goes where you need to go/parking availability), customer service (provided by drivers and other transit service staff), reliability of service (does the service run on time?), ease of use (clear service info, routes easy to figure out, etc.), comfort while waiting at station/stop (shelter from weather, amenities, etc.), and safety while riding the service (safety from accidents and/or crime). The overall opinion is an indicator of customer satisfaction with transit as a whole. The survey instrument is administered in Chinese. It was pretested by transit riders at stations/stops in Shenzhen and Guangzhou. We revised the survey based on their feedback.

When administering the survey, our sampling target was to achieve an equal number of riders for each type of transit. The final data include 492 BRT riders, 499 bus riders, and 482 metro riders. Table 2 compares their socio-demographic characteristics. Household size and income are significantly different among riders of different transits. Bonferroni tests show that bus riders tend to have a larger household than BRT and metro riders whereas there is no difference between the latter two, and metro riders are more affluent than bus and BRT riders but there is no difference between the latter two. 
Table 2: Sample characteristics

\begin{tabular}{llccc}
\hline Variables & Bus & BRT & Metro & p-value \\
\hline Income $^{\#}$ & 4.48 & 4.71 & 4.99 & $0.000^{*}$ \\
Household size & 4.49 & 4.08 & 4.17 & $0.000^{*}$ \\
\# of cars & 0.50 & 0.51 & 0.58 & 0.162 \\
\# of motorcycles & 0.50 & 0.47 & 0.48 & 0.855 \\
Age \# & 2.77 & 2.74 & 2.70 & 0.527 \\
Education \# & 4.01 & 4.06 & 3.92 & 0.116 \\
Female & $44 \%$ & $50 \%$ & $47 \%$ & 0.221 \\
Worker & $78 \%$ & $79 \%$ & $81 \%$ & 0.562 \\
License & $37 \%$ & $37 \%$ & $39 \%$ & 0.950 \\
\hline
\end{tabular}

The p-value is based on ANOVA test.

* significant at the 0.05 level.

\# The variables are measured on ordinal scales. In particular, for income, 1=less than 1,000 Yuan, 2=1,000-1,999 Yuan, 3=2,000-2,999 Yuan, 4=3,000-4,999 Yuan, 5=4,000-4,999 Yuan, 6=5,000-6,999 Yuan, 7=7,000-8,999 Yuan, $8=$ more than 9,000 Yuan. For age, $1=$ under $18,2=18$ to $24,3=25$ to 34 , $4=35$ to $44,5=45$ to $54,6=55$ to $64,7=65$ to $74,8=75$ or older. For education, $1=$ up to the 6 th grade, $2=$ junior high, $3=$ senior high, $4=$ associate degree, $5=$ bachelor's degree, $6=$ graduate degree.

\subsection{Modeling approach}

Following the literature (Azzopardi \& Nash, 2013), this study uses the median performance and median stated importance of the 13 service attributes as the thresholds to construct explicit IPA. For implicit IPA, we use ordered logit models to derive the implicit importance of the 13 attributes (see Appendix Table A1), because overall satisfaction is measured on an ordinal scale (de Oña \& de Oña, 2015). The median of all coefficients is chosen as the threshold of the implicit importance. We expect that the two sets of IPA will yield somewhat different outcomes.

To identify the three factors, we use the median explicit importance and median implicit importance above to construct an importance grid. Refer to Figure 3 and the literature review for the method in detail. When applying regression with dummy variables, we recode " 1 " and " 2 " of the five-point scale into a low performance dummy variable and " 4 " and " 5 " into a high performance dummy variable. With 13 service attributes, we produce 26 dummy variables. Then ordered logit models are developed to test the significance of these dummy variables (see Appendix Table A2). Because of limited sample size, we choose 0.1 as the significance threshold. Based on the significance level of dummy variables, we classify the 13 attributes into basic, performance, and excitement factors. Refer to the literature review for the detailed classification approach.

\section{$4 \quad$ Results}

\subsection{Comparing IPA and the importance grid}

Table 3 presents the outcomes of explicit IPA. For conventional bus, transit agencies should prioritize reliability of transit service and comfort while waiting at station/stop since their importance is larger than the median importance but their performance is lower than the median performance. For BRT, transit agencies should focus on safety while riding the service, safety while at station/stop, and comfort while waiting at station/stop. Convenience of service is an improvement priority for metro transit. 
Table 3: Results of explicit importance-performance analysis

\begin{tabular}{|c|c|c|c|c|c|c|c|c|c|c|c|c|c|c|c|}
\hline \multirow[t]{2}{*}{ Service Attributes } & \multicolumn{5}{|l|}{ Bus } & \multicolumn{5}{|l|}{ BRT } & \multicolumn{5}{|c|}{ Metro } \\
\hline & Perf. & Rank & Imp. & Rank & Group & Perf. & Rank & Imp. & Rank & Group & Perf. & Rank & Imp. & Rank & Group \\
\hline $\begin{array}{l}\text { Safety while riding the } \\
\text { service }\end{array}$ & 3.17 & 4 & 4.64 & 1 & $\mathrm{k}$ & 3.39 & 10 & 4.56 & 1 & f & 3.97 & 7 & 4.56 & 1 & $\mathrm{f}$ \\
\hline $\begin{array}{l}\text { Comfort while waiting } \\
\text { at station/stop }\end{array}$ & 2.79 & 13 & 4.01 & 6 & f & 3.46 & 8 & 4.00 & 6 & f & 4.20 & 2 & 3.92 & 8 & o \\
\hline Ease of service use & 3.22 & 3 & 4.17 & 2 & $\mathrm{k}$ & 3.67 & 2 & 4.21 & 2 & $\mathrm{k}$ & 4.06 & 5 & 4.16 & 4 & $\mathrm{k}$ \\
\hline Reliability of service & 2.91 & 10 & 4.11 & 3 & f & 3.49 & 7 & 4.08 & 3 & $\mathrm{k}$ & 4.01 & 6 & 4.20 & 3 & $\mathrm{k}$ \\
\hline Customer service & 2.88 & 12 & 3.50 & 11 & 1 & 3.23 & 11 & 3.66 & 10 & 1 & 3.72 & 11 & 3.38 & 12 & 1 \\
\hline Convenience of service & 3.26 & 2 & 4.06 & 5 & $\mathrm{k}$ & 3.59 & 3 & 4.05 & 4 & $\mathrm{k}$ & 3.90 & 9 & 4.14 & 5 & f \\
\hline Other riders & 2.88 & 11 & 3.40 & 13 & 1 & 3.11 & 13 & 3.65 & 11 & 1 & 3.44 & 12 & 3.41 & 11 & 1 \\
\hline Hours of service & 3.15 & 5 & 3.50 & 10 & o & 3.51 & 6 & 3.62 & 12 & o & 3.86 & 10 & 3.33 & 13 & 1 \\
\hline Comfort while riding & 2.94 & 9 & 3.72 & 9 & 1 & 3.23 & 12 & 3.75 & 8 & 1 & 3.96 & 8 & 3.76 & 9 & 1 \\
\hline Frequency of service & 3.02 & 8 & 3.96 & 7 & 1 & 3.58 & 5 & 3.98 & 7 & o & 4.18 & 3 & 4.06 & 7 & o \\
\hline Travel cost & 3.72 & 1 & 3.49 & 12 & 0 & 3.79 & 1 & 3.56 & 13 & 0 & 3.43 & 13 & 3.67 & 10 & 1 \\
\hline $\begin{array}{l}\text { Safety while at station/ } \\
\text { stop }\end{array}$ & 3.03 & 7 & 4.10 & 4 & $\mathrm{k}$ & 3.44 & 9 & 4.04 & 5 & f & 4.15 & 4 & 4.24 & 2 & $\mathrm{k}$ \\
\hline $\begin{array}{l}\text { Door to door travel } \\
\text { time }\end{array}$ & 3.04 & 6 & 3.87 & 8 & o & 3.58 & 4 & 3.69 & 9 & o & 4.21 & 1 & 4.12 & 6 & $\mathrm{k}$ \\
\hline
\end{tabular}

Notes:

(1) Perf. = performance; Imp. = explicit importance; $\mathrm{k}=$ keep up the good work; $\mathrm{f}=$ focus here; $\mathrm{l}=$ low priority; $\mathrm{o}=$ possible overkill.

(2) Bolded entries are improvement priorities.

Table 4 presents the results of implicit IPA. In terms of improvement priorities, the implicit IPA produces somewhat similar results to the explicit IPA. For bus, resources should be concentrated on comfort while waiting at station/stop, reliability of service, and customer service. Customer service is classified as low priority in the explicit IPA. For BRT, comfort while riding the service joins safety while riding the service and comfort while waiting at station/stop as an improvement priority. Safety while at station/stop is classified as low priority. For metro transit, convenience of service is still an improvement priority. Overall, the difference between the implicit IPA and explicit IPA is the classification of safety while at station/stop and comfort while riding for BRT and customer service for conventional bus. 
Table 4: Results of implicit importance-performance analysi.

\begin{tabular}{|c|c|c|c|c|c|c|c|c|c|c|c|c|c|c|c|}
\hline Service Attributes & Bus & & & & & BRT & & & & & Metro & & & & \\
\hline & Perf. & Rank & Imp. & Rank & Group & Perf. & Rank & Imp. & Rank & Group & Perf. & Rank & Imp. & Rank & Group \\
\hline $\begin{array}{l}\text { Safety while riding the } \\
\text { service }\end{array}$ & 3.17 & 4 & 0.28 & 7 & o & 3.39 & 10 & 0.55 & 2 & f & 3.97 & 7 & 0.13 & 9 & 1 \\
\hline $\begin{array}{l}\text { Comfort while waiting } \\
\text { at station/stop }\end{array}$ & 2.79 & 13 & 0.57 & 3 & f & 3.46 & 8 & 0.37 & 5 & f & 4.20 & 2 & 0.55 & 3 & $\mathrm{k}$ \\
\hline Ease of service use & 3.22 & 3 & 0.86 & 1 & $\mathrm{k}$ & 3.67 & 2 & 0.55 & 3 & $\mathbf{k}$ & 4.06 & 5 & 0.62 & 2 & $\mathrm{k}$ \\
\hline Reliability of service & 2.91 & 10 & 0.43 & 4 & $\mathbf{f}$ & 3.49 & 7 & 0.32 & 7 & 1 & 4.01 & 6 & 0.07 & 11 & o \\
\hline Customer service & 2.88 & 12 & 0.62 & 2 & $\mathbf{f}$ & 3.23 & 11 & 0.04 & 10 & 1 & 3.72 & 11 & 0.04 & 12 & 1 \\
\hline Convenience of service & 3.26 & 2 & 0.41 & 5 & $\mathrm{k}$ & 3.59 & 3 & 0.57 & 1 & $\mathrm{k}$ & 3.90 & 9 & 0.26 & 6 & $\mathbf{f}$ \\
\hline Other riders & 2.88 & 11 & -0.01 & 12 & 1 & 3.11 & 13 & -0.01 & 11 & 1 & 3.44 & 12 & 0.23 & 8 & 1 \\
\hline Hours of service & 3.15 & 5 & 0.16 & 9 & $\mathrm{o}$ & 3.51 & 6 & & & & 3.86 & 10 & 0.01 & 13 & 1 \\
\hline Comfort while riding & 2.94 & 9 & 0.08 & 11 & 1 & 3.23 & 12 & 0.34 & 6 & $\mathbf{f}$ & 3.96 & 8 & 0.25 & 7 & 1 \\
\hline Frequency of service & 3.02 & 8 & -0.03 & 13 & 1 & 3.58 & 5 & 0.24 & 8 & $\mathrm{o}$ & 4.18 & 3 & 0.68 & 1 & $\mathrm{k}$ \\
\hline Travel cost & 3.72 & 1 & 0.09 & 10 & o & 3.79 & 1 & -0.07 & 12 & o & 3.43 & 13 & 0.10 & 10 & 1 \\
\hline $\begin{array}{l}\text { Safety while at station/ } \\
\text { stop }\end{array}$ & 3.03 & 7 & 0.20 & 8 & 1 & 3.44 & 9 & 0.13 & 9 & 1 & 4.15 & 4 & 0.42 & 5 & $\mathrm{k}$ \\
\hline $\begin{array}{l}\text { Door to door travel } \\
\text { time }\end{array}$ & 3.04 & 6 & 0.35 & 6 & $\mathrm{k}$ & 3.58 & 4 & 0.44 & 4 & $\mathrm{k}$ & 4.21 & 1 & 0.55 & 4 & $\mathrm{k}$ \\
\hline
\end{tabular}

Notes:

(1) Perf. = performance; Imp. = implicit importance; $\mathrm{k}=$ keep up the good work; $\mathrm{f}=$ focus here; $\mathrm{l}=$ low priority; $\mathrm{o}=$ possible overkill.

(2) Bolded entries are improvement priorities.

(3) For BRT, hours of service has a positive bivariate correlation with overall satisfaction but it has a counter-intuitive sign in the ordered logit model and hence is manually removed.

(4) The implicit importance of service attributes is derived from the coefficients in Table A1 in Appendix. Some coefficients have a negative sign and seem to be counterintuitive. However, they are not statistically different from zero.

However, in term of service attribute classification, the explicit IPA and implicit IPA produce somewhat different outcomes. For conventional bus, safety while riding the service is possible overkill based on the implicit IPA but it is in the category of "keep up the good work" based on the explicit IPA. Other discrepancy includes customer service, safety while at station/stop, and travel time for conventional bus, reliability, comfort while riding, safety while at station/stop, and travel time for BRT, and safety while riding the service, comfort while waiting at stop/station, reliability, frequency of service for metro transit. The number of divergent classifications accounts for about $1 / 3$ of all classifications. The divergence is due to the type of importance indicators used to classify service attributes. The implicit IPA should be more reliable results because it relaxes the unrealistic assumption of the explicit IPA. stated importance and performance are independent.

Table 5 illustrates the outcomes of the importance grid. Because it relies on explicit importance, it is not surprising that the improvement priorities identified in the explicit IPA are classified either as key performance factors or basic factors. Because these important factors have relatively inferior performance, they should also be prioritized. Further, because customer service for bus and comfort while riding for BRT have low explicit importance but high implicit importance, they are classified as excitement factors. Overall, the importance grid integrates the outcomes of explicit IPA and implicit IPA and hence is superior to the IPA. 
Table 5: Results of the three-factor approac.

\begin{tabular}{|c|c|c|c|c|c|c|c|c|c|c|c|c|c|c|c|}
\hline Service Attributes & Bus & & & & & BRT & & & & & Metro & & & & \\
\hline & Impl & Rank & Expl & Rank & Group & Impl & Rank & Expl & Rank & Group & Impl & Rank & Expl & Rank & Group \\
\hline $\begin{array}{l}\text { Safety while riding the } \\
\text { service }\end{array}$ & 0.28 & 7 & 4.64 & 1 & $\mathrm{~b}$ & 0.55 & 2 & 4.56 & 1 & $\mathbf{p}$ & 0.13 & 9 & 4.56 & 1 & $\mathrm{~b}$ \\
\hline $\begin{array}{l}\text { Comfort while waiting } \\
\text { at station/stop }\end{array}$ & 0.57 & 3 & 4.01 & 6 & $\mathbf{p}$ & 0.37 & 5 & 4.00 & 6 & $\mathbf{p}$ & 0.55 & 3 & 3.92 & 8 & e \\
\hline Ease of service use & 0.86 & 1 & 4.17 & 2 & $\mathrm{p}$ & 0.55 & 3 & 4.21 & 2 & $\mathrm{p}$ & 0.62 & 2 & 4.16 & 4 & $\mathrm{p}$ \\
\hline Reliability of service & 0.43 & 4 & 4.11 & 3 & $p$ & 0.32 & 7 & 4.08 & 3 & $\mathrm{~b}$ & 0.07 & 11 & 4.20 & 3 & $\mathrm{~b}$ \\
\hline Customer service & 0.62 & 2 & 3.50 & 11 & e & 0.04 & 10 & 3.66 & 10 & & 0.04 & 12 & 3.38 & 12 & \\
\hline Convenience of service & 0.41 & 5 & 4.06 & 5 & $\mathrm{p}$ & 0.57 & 1 & 4.05 & 4 & $\mathrm{p}$ & 0.26 & 6 & 4.14 & 5 & $\mathbf{p}$ \\
\hline Other riders & -0.01 & 12 & 3.40 & 13 & & -0.01 & 11 & 3.65 & 11 & & 0.23 & 8 & 3.41 & 11 & \\
\hline Hours of service & 0.16 & 9 & 3.50 & 10 & & & & 3.62 & 12 & & 0.01 & 13 & 3.33 & 13 & \\
\hline Comfort while riding & 0.08 & 11 & 3.72 & 9 & & 0.34 & 6 & 3.75 & 8 & $\mathbf{e}$ & 0.25 & 7 & 3.76 & 9 & \\
\hline Frequency of service & -0.03 & 13 & 3.96 & 7 & & 0.24 & 8 & 3.98 & 7 & & 0.68 & 1 & 4.06 & 7 & $\mathrm{e}$ \\
\hline Travel cost & 0.09 & 10 & 3.49 & 12 & & -0.07 & 12 & 3.56 & 13 & & 0.10 & 10 & 3.67 & 10 & \\
\hline $\begin{array}{l}\text { Safety while at station/ } \\
\text { stop }\end{array}$ & 0.20 & 8 & 4.10 & 4 & $\mathrm{~b}$ & 0.13 & 9 & 4.04 & 5 & b & 0.42 & 5 & 4.24 & 2 & $\mathrm{p}$ \\
\hline $\begin{array}{l}\text { Door to door travel } \\
\text { time }\end{array}$ & 0.35 & 6 & 3.87 & 8 & e & 0.44 & 4 & 3.69 & 9 & e & 0.55 & 4 & 4.12 & 6 & $\mathrm{p}$ \\
\hline
\end{tabular}

Notes:

(1) Impl = implicit importance or derived importance using ordered logit models in Table A1 in Appendix; Expl = explicit importance or stated importance in the survey; $\mathrm{b}=$ basic factor; $\mathrm{p}=$ key performance factor; $\mathrm{e}=$ excitement factor; empty cells in the Group column indicate unimportant performance factors.

(2) Bolded entries are improvement priorities.

(3) For BRT, hours of service has a positive bivariate correlation with overall satisfaction but it has a counter-intuitive sign in the ordered logit model and hence is manually removed.

(4) The implicit importance of service attributes is derived from the coefficients in Table A1 in Appendix. Some coefficients have a negative sign and seem to be counterintuitive. However, they are not statistically different from zero.

More importantly, the three-factor theory further defines the hierarchy of improvements and suggests to first set priorities to fulfill all basic factors, then provide satisfied key performance factors competitively, and ultimately improve excitement factors (Matzler et al., 2003). In this study, the first priority for bus should be on comfort while waiting at station/stop and reliability of service. Because customer service is an excitement factor with low performance, transit agencies could try to improve it if resources are available. For BRT, because safety while at station/stop is a basic factor, it is on the first tier of improvement priorities, followed by the underperformed key performance factors (safety while riding the service and comfort while waiting at station/stop) and then the underperformed excitement factor (comfort while riding).

It is worth noting that when deciding improvement priorities, we choose the median performance of all 13 service attributes as the threshold. If the threshold is chosen as the average performance of 3 , all attributes of both BRT and metro transit exceed it. That is, BRT and metro transit riders on average are satisfied with the attributes. However, the threshold change will not affect the outcome for bus. Because the threshold choice affects results, it should be based on the local context and goals of transit agencies in planning practices.

\subsection{Further exploration of the three-factor theory}

Table 6 compares the results of three-factor classification using two approaches. the importance grid and regression with dummy variables. Refer to Appendix Table A2 for details about the ordered logit 
models associated with the latter approach. Conceptually, the importance grid produces better results than regression with dummy variables. For example, the importance grid classifies both safety attributes (while riding the service or at station/stop) as either basic factors or performance factors. Using regression with dummy variables, they are mostly classified as excitement factors. This does not make sense because of individuals' fundamental needs for safety features (Matzler et al., 2003; Yoh, Iseki, Smart, \& Taylor, 2011). Therefore, although Busacca and Padula (2005) concluded that regression with dummy variables is a better approach than the importance grade, it does not hold in this study. This discrepancy calls for additional theoretical studies in the field of marketing. Our further discussion will focus on the outcomes from the importance grid.

Table 6. Comparing the importance grid and regression with dummy variables

\begin{tabular}{l|cc|cc|cc}
\hline & Bus & & BRT & & Metro & \\
& Imp. & Reg. & Imp. & Reg. & Imp. & Reg. \\
\hline Safety while riding the service & $\mathbf{b}$ & $\mathbf{e}$ & $\mathbf{p}$ & $\mathbf{e}$ & $\mathbf{b}$ & \\
Comfort while waiting at station/stop & $\mathbf{p}$ & $\mathbf{b}$ & $\mathbf{p}$ & $\mathbf{e}$ & $\mathrm{e}$ & $\mathrm{e}$ \\
Ease of service use & $\mathrm{p}$ & $\mathrm{p}$ & $\mathbf{p}$ & $\mathbf{e}$ & $\mathbf{p}$ & $\mathbf{e}$ \\
Reliability of service & $\mathbf{p}$ & $\mathbf{e}$ & $\mathbf{b}$ & $\mathbf{e}$ & $\mathbf{b}$ & \\
Customer service & $\mathbf{e}$ & $\mathbf{b}$ & & & & \\
Convenience of service & $\mathbf{p}$ & $\mathbf{b}$ & $\mathrm{p}$ & $\mathrm{p}$ & $\mathbf{p}$ & $\mathbf{e}$ \\
Other riders & & & & & & \\
Hours of service & & & & & & \\
Comfort while riding & & & $\mathrm{e}$ & $\mathrm{e}$ & & $\mathbf{e}$ \\
Frequency of service & & & & $\mathbf{e}$ & $\mathbf{e}$ & \\
Travel cost & & & & & & $\mathbf{e}$ \\
Safety while at station/stop & $\mathbf{b}$ & $\mathbf{e}$ & $\mathbf{b}$ & $\mathbf{e}$ & $\mathbf{p}$ & $\mathbf{b}$ \\
Door to door travel time & $\mathrm{e}$ & $\mathrm{e}$ & $\mathbf{e}$ & $\mathbf{b}$ & $\mathbf{p}$ & $\mathbf{e}$ \\
\hline
\end{tabular}

Notes:

(1) Imp. = the importance grid; Reg. = regression with dummy variables;

(2) $\mathrm{b}$ = basic factor; $\mathrm{p}=$ key performance factor; $\mathrm{e}=$ excitement factor; empty cells indicate unimportant performance factors.

For all three types of transit, safety while riding the service, safety while at station/stop, ease of service use, reliability, and convenience of service are classified as either basic factors or key performance factors. These highlight the importance of safety, reliability, service coverage and information (spatial and information availability). Comfort while waiting at station/stop is a performance factor for conventional bus and BRT, but it is an excitement factor for metro transit. Waiting time is more important than in-vehicle travel time (TCRP, 2003) and amenities at station/stop influence riders' perception of waiting time (Fan, Guthrie, \& Levinson, 2016). Therefore, comfort while waiting is important for transit riders. Because waiting for metro transit is in an enclosed area with many amenities, waiting becomes less important to metro transit than bus and BRT. Door to door travel time is the sixth key attribute for metro transit. This is reasonable because one of the important feature of metro transit is its segregated right of way and it travels faster than other types of transit. Although BRT has dedicated right of way within the trunk line, it operates along with other bus services in bus-only lanes (where right turns are allowed) outside of the trunk line. Therefore, it is not surprising that travel time is classified an excitement factor, rather than a performance factor. Travel time does improve overall satisfaction of BRT riders as it performs well. Travel time for conventional bus shows a similar pattern to BRT. Again, comfort while riding is an excitement factor for BRT and customer service is an excitement factor for conventional bus, but they are unimportant performance factors for the other two types of services, respectively. Frequency of service is an excitement factor for metro transit and it contributes to the satisfaction of metro riders. 


\section{$5 \quad$ Conclusions}

Customer satisfaction surveys have been used to evaluate transit quality of service. However, previous research effort has been limited to examine the relative importance of service attributes and identify service improvement priorities using importance-performance analysis. Few studies in the field of transportation have applied the three-factor theory, which is prevalent in the marketing literature. Using transit rider survey data from Guangzhou, this study compares and discusses the results obtained through the IPA and the three-factor theory.

This study first compares the results of explicit IPA and implicit IPA. About 1/3 of 39 combinations (covering 13 attributes for bus, BRT, and metro transit) are classified differently by the two approaches. The differences result from the ways in which the importance of service attributes are used. Implicit IPA is presumably more reliable than explicit IPA. In term of improvement priorities, the two approaches yield somewhat similar results, although there are incongruences with three attributes. Combined with attribute performance, the importance grid produces eight service improvement priorities for the three types of transit. For bus, in particular, comfort while waiting at station/stop and service reliability should be prioritized, followed by customer service if resources are abundant; for BRT, safety while at station/stop should be the first priority, followed by safety while riding the service and comfort while waiting at station/stop, and then comfort while riding if extra resources are available; for metro transit, the improvement should focus on convenience of service (spatial coverage). It is worth noting that the recommendations are based on subjective views of transit riders and do not consider improvement costs. Transit agencies should comprehensively evaluate benefits and costs of these attributes and promote more cost-effective strategies.

This study also compares the outcomes using the importance grid and regression with dummy variables. Although Busacca and Padula (2005) suggest the superiority of the latter approach, this study concludes that the former approach produces more reasonable results. However, because this is the only comparison in the transit field, duplicative studies are required to validate this conclusion. On the other hand, due to the constraint of survey lengths, transit rider satisfaction surveys often drop explicitlystated importance (Guirao et al., 2016). Scholars have to rely on regression with dummy variables to classify the three factors of transit service. Therefore, additional methodological research is necessary to understand why the two approaches produce divergent results.

Based on the Guangzhou data, this study finds that seven service attributes are important for overall satisfaction with all three types of transit, although the extent of importance varies by different transits. The attributes consist of safety while riding the service, safety while at station/stop, comfort while waiting at station/stop, ease of service use (information availability), door to door travel time, reliability, and convenience of service. Further, customer service for bus, comfort while riding for BRT, and frequency of service for metro transit are also important. Transit agencies should pay attention to these service attributes when designing and improving their transit services. On the other hand, transit rider with different characteristics such as demographics may value different dimensions of transit service. Future studies should apply the IPA and three-factor theory to examine different segments of riders (de Oña, de Oña, Eboli, \& Mazzulla, 2015; dell'Olio et al., 2010; Verbich \& El-Geneidy, 2016). It is worth noting that in terms of factor classification, BRT is more similar to conventional bus than metro transit although BRT is often advertised as "train on rubber tires..

Overall, the IPA is better than the studies that explore only the relative importance of service attributes because it informs transit agencies which attributes should be prioritized given limited funding sources. The three-factor theory is superior to the IPA as it relaxes the unrealistic assumption intrinsic to the IPA. service attributes have a linear and symmetric influence on overall satisfaction. 


\section{Acknowledgments}

This research was supported by the US National Science Foundation (PIRE \#1243535 and SRN \#1444745 ) and the National Natural Science Foundation of China (No. 41171139 and 41130747). Chen Zhang and Ajay Nagpure helped survey design and Jieyu Liu helped supervise data collection. 


\section{References}

Azzopardi, E., \& Nash, R. (2013). A critical evaluation of importance-performance analysis. Tourism Management, 35, 222-233. doi: http://dx.doi.org/10.1016/j.tourman.2012.07.007

Busacca, B., \& Padula, G. (2005). Understanding the relationship between attribute performance and overall satisfaction: Theory, measurement and implications. Marketing Intelligence and Planning, 23(6), 543-561. doi:10.1108/02634500510624110

Cain, A., Flynn, J., McCourt, M., \& Reyes, T. (2009). Quantifying the Importance of Image and Perception to Bus Rapid Transit. Washington, DC: U.S. Department of Transport Federal Transit Administration.

Cao, J., Cao, X., Zhang, C., \& Huang, X. (2016). The gaps in satisfaction with transit services among BRT, metro, and bus riders: Evidence from Guangzhou. Journal of Transport and Land Use, 9(3), 97-109.

de Oña, J., \& de Oña, R. (2015). Quality of service in public transport based on customer satisfaction surveys: A review and assessment of methodological approaches. Transportion Science, 49(3), 605-622.

de Oña, J., de Oña, R., Eboli, L., \& Mazzulla, G. (2015). Heterogeneity in Perceptions of Service Quality among Groups of Railway Passengers. International Journal of Sustainable Transportation, 9(8), 612-626. doi:10.1080/15568318.2013.849318

dell'Olio, L., Ibeas, A., \& Cecin, P. (2011). The quality of service desired by public transport users. Transport Policy, 18(1), 217-227. doi:http://dx.doi.org/10.1016/j.tranpol.2010.08.005

dell'Olio, L., Ibeas, A., \& Cecín, P. (2010). Modelling user perception of bus transit quality. Transport Policy, 17(6), 388-397. doi:http://dx.doi.org/10.1016/j.tranpol.2010.04.006

Eboli, L., \& Mazzulla, G. (2007). Service Quality attributes affecting customer satisfaction for bus transit. Journal of Public Transportation, 10(3), 21-34.

Eboli, L., \& Mazzulla, G. (2015). Relationships between rail passengers' satisfaction and service quality: A framework for identifying key service factors. Public Transport, 7(2), 185-201. doi:10.1007/ s12469-014-0096-x

Fan, Y., Guthrie, A., \& Levinson, D. (2016). Waiting time perceptions at transit stops and stations: Effects of basic amenities, gender, and security. Transportation Research Part A: Policy and Practice, 88, 251-264. doi:http://dx.doi.org/10.1016/j.tra.2016.04.012

Figler, S., Sriraj, P., Welch, E., \& Yavuz, N. (2011). Customer loyalty and Chicago, Illinois, Transit Authority buses. Transportation Research Record, 2216, 148-156. doi:10.3141/2216-16

Grisé, E., \& El-Geneidy, A. (2017). Evaluating the relationship between socially (dis)advantaged neighbourhoods and customer satisfaction of bus service in London, U.K. Journal of Transport Geography, 58, 166-175. doi:http://dx.doi.org/10.1016/j.jtrangeo.2016.11.016

Guirao, B., García-Pastor, A., \& López-Lambas, M. E. (2016). The importance of service quality attributes in public transportation: Narrowing the gap between scientific research and practitioners' needs. Transport Policy, 49, 68-77. doi:http://dx.doi.org/10.1016/j.tranpol.2016.04.003

Hensher, D. A., Mulley, C., \& Yahya, N. (2010). Passenger experience with quality-enhanced bus service: The tyne and wear 'superoute' services. Transportation, 37(2), 239-256. doi:10.1007/s11116009-9240-x

Iseki, H., \& Taylor, B. D. (2010). Style versus service? An analysis of user perceptions of transit stops and stations. Journal of Public Transportation, 13(3), 23-48.

Kano, N., Seraku, N., Takahashi, F., \& Tsuji, S. (1984). Attractive quality and must-be quality. Hinshitsu, 14(2), 147-156. 
Martilla, J. A., \& James, J. C. (1977). Importance-performance analysis. Journal of Marketing, 41(1), 77-79. doi:10.2307/1250495

Matzler, K., Bailom, F., Hinterhuber, H. H., Renzl, B., \& Pichler, J. (2004). The asymmetric relationship between attribute-level performance and overall customer satisfaction: A reconsideration of the importance-performance analysis. Industrial Marketing Management, 33(4), 271-277. doi:http:// dx.doi.org/10.1016/S0019-8501(03)00055-5

Matzler, K., Sauerwein, E., \& Heischmidt, K. (2003). Importance-performance analysis revisited: The role of the factor structure of customer satisfaction. The Service Industries Journal, 23(2), 112-129. doi:10.1080/02642060412331300912

Mouwen, A. (2015). Drivers of customer satisfaction with public transport services. Transportation Research Part A: Policy and Practice, 78, 1-20. doi:http://dx.doi.org/10.1016/j.tra.2015.05.005

Ojo, T. K. (2017). Quality of public transport service: An integrative review and research agenda. Transportation Letters, 1-14. doi:10.1080/19427867.2017.1283835

Shen, W., Xiao, W., \& Wang, X. (2016). Passenger satisfaction evaluation model for Urban rail transit: A structural equation modeling based on partial least squares. Transport Policy, 46, 20-31. doi:http:// dx.doi.org/10.1016/j.tranpol.2015.10.006

TCRP (Transit Cooperative Research Program). (2003). Transit Capacity and Quality of Service Manual. Washington, DC: Transportation Research Board.

Tyrinopoulos, Y., \& Antoniou, C. (2008). Public transit user satisfaction: Variability and policy implications. Transport Policy, 15(4), 260-272. doi:http://dx.doi.org/10.1016/j.tranpol.2008.06.002

van Lierop, D., \& El-Geneidy, A. (2016). Enjoying loyalty: The relationship between service quality, customer satisfaction, and behavioral intentions in public transit. Research in Transportation Economics, 59, 50-59. doi:http://dx.doi.org/10.1016/j.retrec.2016.04.001

Vavra, T. G. (1997). Improving your measurement of customer satisfaction: A guide to creating, conducting, analyzing, and reporting customer satisfaction measurement programs. Milwaukee, WI: ASQ Quality Press.

Verbich, D., \& El-Geneidy, A. (2016). The pursuit of satisfaction: Variation in satisfaction with bus transit service among riders with encumbrances and riders with disabilities using a large-scale survey from London, UK. Transport Policy, 47, 64-71. doi:http://dx.doi.org/10.1016/j.tranpol.2015.12.009

Weinstein, A. (2000). Customer satisfaction among transit riders: How customers rank the relative importance of various service attributes. Transportation Research Record, 1735, 123-132. doi:10.3141/1735-15

Yoh, A., Iseki, H., Smart, M., \& Taylor, B. (2011). Hate to wait: Effects of wait time on public transit travelers' perceptions. Transportation Research Record, 2216, 116-124. doi:10.3141/2216-13

Zhang, C., \& Nagpure, A. (2015). Exploring quality of service of BRT and conventional buses in Indore, India: An Application of importance-performance analysis. Paper presented at the 55th ACSP Annual Conference, Houston, TX. 


\section{Appendix}

Table A1: Ordered logit models for overall satisfaction for different services

\begin{tabular}{|c|c|c|c|c|c|c|}
\hline & \multicolumn{2}{|l|}{ Bus } & \multicolumn{2}{|l|}{ BRT } & \multicolumn{2}{|l|}{ Metro } \\
\hline & Beta & $\mathrm{P}$ & Beta & $\mathrm{P}$ & Beta & $\mathrm{P}$ \\
\hline Safety while riding the service & 0.28 & 0.09 & 0.14 & 0.29 & 0.13 & 0.37 \\
\hline Comfort while waiting at station/stop & 0.57 & 0.00 & 0.37 & 0.01 & 0.55 & 0.00 \\
\hline Ease of service use & 0.86 & 0.00 & 0.55 & 0.00 & 0.62 & 0.00 \\
\hline Reliability of service & 0.43 & 0.01 & 0.32 & 0.03 & 0.07 & 0.67 \\
\hline Customer service & 0.62 & 0.00 & 0.04 & 0.76 & 0.04 & 0.81 \\
\hline Convenience of service & 0.41 & 0.01 & 0.57 & 0.00 & 0.26 & 0.06 \\
\hline Other riders & -0.01 & 0.97 & -0.01 & 0.96 & 0.23 & 0.10 \\
\hline Hours of service & 0.16 & 0.20 & & & 0.01 & 0.97 \\
\hline Comfort while riding & 0.08 & 0.61 & 0.34 & 0.02 & 0.25 & 0.07 \\
\hline Frequency of service & -0.03 & 0.83 & 0.24 & 0.06 & 0.68 & 0.00 \\
\hline Travel cost & 0.09 & 0.40 & -0.07 & 0.53 & 0.10 & 0.34 \\
\hline Safety while at station/stop & 0.20 & 0.17 & 0.13 & 0.31 & 0.42 & 0.01 \\
\hline Door to door travel time & 0.35 & 0.02 & 0.44 & 0.00 & 0.55 & 0.00 \\
\hline Threshold 1 & 6.31 & & 5.07 & & 9.12 & \\
\hline Threshold 2 & 9.31 & & 7.50 & & 9.90 & \\
\hline Threshold 3 & 14.11 & & 11.74 & & 12.84 & \\
\hline Threshold 4 & 17.95 & & 15.64 & & 16.81 & \\
\hline Number of observations & 465 & & 487 & & 454 & \\
\hline Pseudo $\mathrm{R}^{2}$ & 0.31 & & 0.26 & & 0.31 & \\
\hline
\end{tabular}

Note: For BRT, hours of service has a positive bivariate correlation with overall satisfaction but it has a counter-intuitive sign in the ordered logit model and hence is manually removed. 
Table A2: Ordered logit models with dummy variables for overall satisfaction for different services

\begin{tabular}{|c|c|c|c|c|c|c|c|c|c|c|c|c|c|c|c|}
\hline & $\begin{array}{l}\text { Bus } \\
\text { Low }\end{array}$ & & High & & & $\begin{array}{l}\text { BRT } \\
\text { Low }\end{array}$ & & High & & & $\begin{array}{c}\text { Metro } \\
\text { Low }\end{array}$ & & High & & \\
\hline & Beta & $\mathrm{P}$ & Beta & $\mathrm{P}$ & Group & Beta & $\mathrm{P}$ & Beta & $\mathrm{P}$ & Group & Beta & $\mathrm{P}$ & Beta & $\mathrm{P}$ & Group \\
\hline $\begin{array}{l}\text { Safety while riding the } \\
\text { service }\end{array}$ & -0.11 & 0.74 & 0.72 & 0.02 & e & -0.16 & 0.63 & 0.81 & 0.00 & $\mathrm{e}$ & 0.91 & 0.10 & 0.30 & 0.25 & \\
\hline $\begin{array}{l}\text { Comfort while waiting at } \\
\text { station/stop }\end{array}$ & -1.08 & 0.00 & -0.23 & 0.46 & b & -0.57 & 0.11 & 0.47 & 0.04 & $\mathrm{e}$ & 0.40 & 0.55 & 0.85 & 0.01 & $\mathrm{e}$ \\
\hline Ease of service use & -1.47 & 0.00 & 0.92 & 0.00 & $\mathrm{p}$ & 0.22 & 0.67 & 0.84 & 0.00 & $\mathrm{e}$ & -0.46 & 0.42 & 0.56 & 0.05 & e \\
\hline Reliability of service & -0.13 & 0.66 & 0.91 & 0.01 & $\mathrm{e}$ & -0.41 & 0.32 & 0.42 & 0.09 & $\mathrm{e}$ & 0.26 & 0.70 & 0.41 & 0.13 & \\
\hline Customer service & -0.98 & 0.00 & 0.50 & 0.11 & $\mathrm{~b}$ & 0.08 & 0.81 & 0.08 & 0.76 & & 0.46 & 0.36 & 0.03 & 0.90 & \\
\hline Convenience of service & -0.67 & 0.05 & 0.10 & 0.71 & $\mathrm{~b}$ & -0.99 & 0.03 & 0.77 & 0.00 & $\mathrm{p}$ & 0.23 & 0.66 & 0.69 & 0.00 & e \\
\hline Other riders & 0.02 & 0.96 & -0.44 & 0.18 & & -0.15 & 0.60 & 0.01 & 0.97 & & -0.17 & 0.63 & 0.35 & 0.13 & \\
\hline Hours of service & -0.04 & 0.89 & 0.21 & 0.44 & & -0.13 & 0.77 & -0.17 & 0.45 & & 0.31 & 0.61 & 0.35 & 0.13 & \\
\hline Comfort while riding & -0.43 & 0.16 & 0.18 & 0.53 & & -0.10 & 0.75 & 0.49 & 0.05 & e & 0.51 & 0.30 & 0.88 & 0.00 & e \\
\hline Frequency of service & -0.09 & 0.74 & 0.33 & 0.24 & & 0.13 & 0.74 & 0.46 & 0.05 & $\mathrm{e}$ & 0.13 & 0.89 & 0.48 & 0.10 & \\
\hline Travel cost & -0.11 & 0.76 & 0.32 & 0.21 & & 0.42 & 0.32 & 0.23 & 0.34 & & 0.01 & 0.97 & 0.62 & 0.01 & e \\
\hline Safety while at station/stop & 0.01 & 0.98 & 0.69 & 0.02 & $\mathrm{e}$ & 0.20 & 0.56 & 0.48 & 0.04 & e & -1.93 & 0.01 & 0.39 & 0.19 & $\mathrm{~b}$ \\
\hline Door to door travel time & -0.30 & 0.30 & 0.71 & 0.01 & $\mathrm{e}$ & -0.96 & 0.02 & 0.22 & 0.34 & $\mathrm{~b}$ & -1.34 & 0.08 & 0.84 & 0.01 & $\mathrm{e}$ \\
\hline Threshold 1 & -5.80 & & & & & -4.57 & & & & & -1.64 & & & & \\
\hline Threshold 2 & -3.07 & & & & & -2.27 & & & & & -0.82 & & & & \\
\hline Threshold 3 & 2.09 & & & & & 1.93 & & & & & 2.25 & & & & \\
\hline Threshold 4 & 5.68 & & & & & 5.68 & & & & & 5.73 & & & & \\
\hline Number of observations & 465.00 & & & & & 487 & & & & & 454 & & & & \\
\hline Pseudo R2 & 0.37 & & & & & 0.24 & & & & & 0.22 & & & & \\
\hline
\end{tabular}

Note:

(1) Low = low performance dummy; High = high performance dummy.

(2) $\mathrm{b}$ = basic factor; $\mathrm{p}=$ key performance factor; $\mathrm{e}=$ excitement factor; empty cells in the Group column indicate unimportant performance factors. 